\title{
In vitro antimicrobial activity of solvent extracts of marine brown alga, Hydroclathrus clathratus (C. Agardh) M. Howe from Gulf of Mannar.
}

\author{
T. Vimala*, T. V. Poonghuzhali \\ Department of Botany, Queen Mary's College, Chennai- 600004, India.
}

\section{ARTICLE INFO \\ Article history: \\ Received on: 31/01/2017 \\ Accepted on: 21/03/2017 \\ Available online: $30 / 04 / 2017$}

\section{Key words:}

Seaweed, Hydroclathrus

clathratus, Antibacterial activity, antifungal activity, Gulf of Mannar.

\begin{abstract}
Objective: To evaluate the antimicrobial activity of different extracts of Hydroclathrus clathratus (C. Agardh) M. Howe against human bacterial and fungal pathogens.

Methods: The antimicrobial activities of the extracts against various pathogens were tested by using agar well diffusion method.

Results: Maximum activities were recorded by methanolic extract on P. aeruginosa $(26.33 \pm 1.86 \mathrm{~mm})$, S.aureus $(21.00 \pm 1.78 \mathrm{~mm})$, E. coli $(19.32 \pm 0.89 \mathrm{~mm})$, B. subtilis $(18.33 \pm 1.86 \mathrm{~mm})$ and K. Pneumoneae $(18.14 \pm 1.50 \mathrm{~mm})$. Hexane extract showed maximum antifungal activity against $F$. oxysporum $(18.33 \pm 1.86 \mathrm{~mm})$ and ethyl acetate showed maximum activity against $A$. niger $(18.33 \pm 2.73 \mathrm{~mm})$. While, methanolic extract showed more activity against A. flavus $(18.00 \pm 3.22 \mathrm{~mm})$, C. albicans $(18.14 \pm 1.50 \mathrm{~mm})$ and Penicillium sp. $(13.66 \pm 1.36 \mathrm{~mm})$. However, aqueous extract showed minimum inhibitory effect on the pathogens.

Conclusions: Different solvent extracts of seaweeds used in the present study have shown significant antibacterial and anti-fungal action. The study offers opportunities for producing new types of bioactive compounds; however, the mechanism of inhibition and stability of the extracts still are not clear and more studies should be involved.
\end{abstract}

\section{INTRODUCTION}

Marine algae are considered as one of the largest producers of biomass in the marine environment. They produce a great variety of structurally unique secondary metabolites with pharmacological and biological activities (Schwartsmann et al., 2001). Various natural antimicrobial compounds have been recorded in marine environment more than those in the terrestrial one (Ireland et al., 1988). Seaweeds have been considered as potential sources of the antibiotic substances. Some macroalgae

\footnotetext{
* Corresponding Author

Email:vmm96@ hotmail.com
}

have bio-active components which affected the growth of some pathogenic bacteria (Kolanjinathan et al., 2009). Microbial infection causes high rate of mortality in human population and aquaculture organisms. Modern therapy for infectious diseases by the use of antimicrobial drugs has certain limitations due to changing patterns of resistance in pathogens and the side effects they produced. Development of resistance by pathogens to commonly used antibiotics provides an impetus for attempts to search for new antimicrobial agents to combat infections and overcome the problems of resistance and side effects of the currently available antimicrobial agents. Pharmaceutical industries are giving importance to the compounds derived from natural sources. 
Hence, the systematic screening of marine algae with the purpose of search for components with antimicrobial activity has gained increasing importance in recent times (Mouhssen Lahlou 2013; Kolanjinathan et al., 2014).

There are numerous reports with reference to several pathogen inhibitory compounds from marine macroalgae against human viral, microbial, fungi and yeast pathogens. The extracts of various marine algae have been shown to exhibit antibacterial activity against Gram positive and Gram negative bacteria (LimaFilho et al., 2002).

Brown algae are a large group of mostly marine multicellular algae possessing a wide range of bioactive secondary metabolites. They play an important role in marine environments, both as food and for the habitats they form. Various bioactivities of compounds from brown algae have been extensively reported (Fang et al., 2015; Manilal et al., 2016; Gupta et al., 2011) Among all the seaweeds, highest phytochemical content have been reported from brown seaweeds (Seafoodplus, 2008). Phenolic compounds which play a major role in antibacterial and antifungal activities are found abundantly in brown seaweeds when compared with the green and red seaweeds (Chkhikvishvili and Ramazanov, 2000).

However, the potent antimicrobial effect of seaweeds resides in the efficiency of the extraction method (Tuney et al., 2006), the algal species (Valchos et al., 1997) and the solvents being used (Cox et al., 2010). Studies also have shown that higher medicinal effect was obtained from dry seaweeds samples than from fresh samples as indicated by many studies which reported that extracts prepared from fresh seaweeds showed negligible antimicrobial activity compared to that obtained from dried seaweeds (Manivannan et al., 2011).

The present study aimed to test the in vitro antimicrobial effects of different solvent extracts of brown alga, Hydroclathrus clathratus (C. Agardh) M.Howe isolated from southern part of Tamilnadu, India, against some bacterial and fungal isolates. There are very few reports on this alga and hence the study may provide some insight into the activity of this seaweed.

\section{MATERIALS AND METHODS}

\section{Collection of seaweed}

Fresh, matured and healthy seaweed was collected from Mandapam, Ramanathapuram district of Tamilnadu coast of India during November, 2014. Algal sample was handpicked, washed thoroughly with seawater to remove all the impurities, sand particles and epiphytes, extraneous matter and necrotic were removed. Samples were collected in sterilized polyethylene bags, and put in an ice box, then transferred to the laboratory immediately until the experimental work was done. The alga collected was identified as Hydroclathrus clathratus (C. Agardh) M.Howe and was authenticated by Botanical Survey of India, Southern Regional Centre, Coimbatore, Tamilnadu, India. The specimen has been submitted to the institute for preservation.

\section{Sample preparation}

The sample was gently rinsed with sterile distilled water to remove salt, sand and epiphytes, epizoones, animal castings, calcareous and other adhering detritus matters. The seaweed was then shade dried at room temperature for a span of one week to prevent photolysis and thermal degradation, under a continuous stream of air flow. The completely dried seaweed material was weighed and powdered in a mechanical grinder and then stored at $-20^{\circ} \mathrm{C}$ for further analysis.

\section{Extraction of $\boldsymbol{H}$. clathratus (C. Agardh) M. Howe}

$100 \mathrm{~g}$ of powdered seaweed sample was soaked in the organic solvents with the increasing order of polarity viz., hexane, ethyl acetate and methanol (1:4 w/v), and extracted for 4 days at room temperature, and the extracts were collected and concentrated. Each time before extracting with next solvent powdered was dried in an air oven below $50{ }^{\circ} \mathrm{C}$. Finally, the sample was macerated with water for 24 hour to obtain the aqueous extract. The extract was stored in air tight glass container at $4-8{ }^{\circ} \mathrm{C}$ for further analysis.

\section{Preliminary Phytochemical Screening of the algal extracts}

Preliminary phytochemical screening of different solvent extracts of $H$. clathratus (C. Agardh) M. Howe was carried out to detect the phytoconstituents using standard conventional protocols (Harborne, 1998).

\section{Antimicrobial Activity \\ Bacterial strains}

The bacterial strains used for anti-bacterial assay were obtained from the Institute of Microbial Technology, Chandigarh, India. The following strains were used: Gram negative rods: Escherichia coli (MTCC 43), Pseudomonas aeruginosa (MTCC 1688), Klebsiella pneumoneae (MTCC 432), Gram positive sporeforming rods: Bacillus subtilis (MTCC 441), Gram positive cocci: Staphylococcus aureus (MTCC 737).

\section{Fungal strains}

The fungal strains were obtained from Centre for Advanced Studies in Botany, University of Madras, Tamilnadu, India. The fungal strains used for anti-fungal assay were: Aspergillus flavus, Aspergillus niger, Candida albicans, Fusarium oxysporum, Penicillium sp..

\section{Antibacterial assay}

Antibacterial activity was assayed using the agar well diffusion test technique (Perez et al., 1990). Nutrient Agar Medium (NA) plates were prepared and the $\mathrm{pH}$ was maintained at 7.4. A sterile cotton swab was used for spreading the test pathogen from the 24 hours inoculated broth evenly on the NA plates. Similarly swabbing was done separately for each test pathogen on the NA plates and left for few minutes to allow complete absorption of the inoculums. In each of these plates five wells of $5 \mathrm{~mm}$ diameter each were made using an appropriate size sterilized 
cork borer. $100 \mu \mathrm{l}$ of three different concentrations $(5 \mathrm{mg} / \mathrm{ml}, 2.5$ $\mathrm{mg} / \mathrm{ml}$ and $1.25 \mathrm{mg} / \mathrm{ml}$ respectively) were placed in the wells and allowed to diffuse at $4{ }^{\circ} \mathrm{C}$ temperature for 30 minutes. Antibiotic chloramphenicol $(0.01 \mathrm{mg} / \mathrm{ml})$ was used as positive control and the respective solvents were used as negative control. The extract loaded plates were kept for incubation at $37^{\circ} \mathrm{C}$ for 24 hours. After incubation, a clear zone was observed around the well which was evidence for the presence of antibacterial active compounds in the algal extracts. Diameters of the zone of inhibition were measured in $\mathrm{mm}$.

\section{Antifungal Assay}

Antifungal activity was evaluated by agar diffusion method (Suay et al., 2000). The agar plates inoculated with the test fungi were incubated for $1 \mathrm{~h}$ before placing extracts, following this spots of $25 \mu \mathrm{L}$ of crude extract of seaweed were applied on agar medium. After incubation at $28^{\circ} \mathrm{C} \pm 0.1$ for $48 \mathrm{~h}$, all plates were observed for zones of growth inhibition, and the diameters of these zones were measured in millimeters. All tests were performed on sterile conditions in duplicate and repeated three times. Clotrimazole was used as positive control and respective solvents as negative control.

\section{RESULTS}

\section{Preliminary Phytochemical Screening of the algal extracts}

By preliminary phytochemical screening of fourteen different chemical compounds (steroids, alkaloids, phenolic groups, saponins, tannin, flavonoids, anthraquinone, coumarins, phytosteroids, glycosides, cardiac-glycosides, terpenoids, quinones) were tested in four different extracts of H.clathratus. Thus, out of 56 tests for compounds, only 33 gave positive results and the remaining 23 gave negative results. The positive results showed the presence of tannins, saponins, flavonoids, alkaloids, phenols, cardiac glycosides, terpenoids, Coumarins, steroids, phytosteroids, Anthroquinones, Phlobatannins. Glycosides and quinones did not show in any of the extracts. Flavonoids, Phenols,
Alkaloids, Terpenoids showed the maximum presence in all the four different extracts. Coumarins and phytosteroids were present in 3 different extracts.

Among the four extracts, methanolic extract showed maximum number (11) compounds followed by hexane and ethyl acetate ( 9 compounds) extracts. Aqueous extract showed the minimum number (4) compounds (Table 1).

\section{Antibacterial assay}

The antibacterial activity of H.clathratus extracts was studied by using different solvents viz., aqueous, methanol, ethyl acetate, hexane by agar well diffusion test technique (Perez et al., 1990) against three human pathogens. Table 2 demonstrates the in vitro antimicrobial activity of different extracts of H.clathratus. Among the four solvents tested, methanol extract exhibited maximum inhibition on the growth of the tested bacterial species. As observed, the methanol extract showed the highest inhibitory activity for the chosen bacterial strains followed by other solvent extracts. Maximum activities were recorded by methanolic extract on $P$. aeruginosa $(26.33 \pm 1.86 \mathrm{~mm})$, S.aureus $(21.00 \pm 1.78 \mathrm{~mm})$, E.coli $(19.32 \pm 0.89 \mathrm{~mm})$, B.subtilis $(18.33 \pm 1.86 \mathrm{~mm})$ and $K$. Pneumoneae $(18.14 \pm 1.50 \mathrm{~mm})$. Hexane and ethyl acetate too had maximum inhibitory effect on tested $E$ coli. However, aqueous extract showed minimum inhibitory effect on the pathogens.

\section{Antifungal assay}

Antifungal activity was evaluated by agar diffusion method (Suay et al., 2000). The present study is an attempt to screen antifungal activities of H.clathratus through crude extracts of different solvents on fungal strains viz., Aspergillus flavus, Aspergillus niger, Candida albicans, Fusarium oxysporum, Penicillium sp. (Table 3). Hexane extract showed maximum activity against $F$. oxysporum $(18.33 \pm 1.86 \mathrm{~mm})$ and ethyl acetate showed maximum activity against A.niger $(18.33 \pm 2.73 \mathrm{~mm})$. However, methanolic extract showed more activity against A.flavus $(18.00 \pm 3.22 \mathrm{~mm})$, C.albicans $(18.14 \pm 1.50 \mathrm{~mm})$ and Penicillium sp. $(13.66 \pm 1.36 \mathrm{~mm})$.

Table 1: Phytochemical screening of different solvents extract of H.clathratus.

\begin{tabular}{|c|c|c|c|c|}
\hline Phytochemical tests & Hexane & Ethyl acetate & Methanol & Aqueous \\
\hline Tannins & + & + & + & - \\
\hline Saponins & + & + & - & - \\
\hline Flavonoids & + & + & + & + \\
\hline Alkaloids & + & + & + & + \\
\hline Phenols & + & + & + & + \\
\hline Glycosides & - & - & - & - \\
\hline Cardiac Glycosides & - & + & + & - \\
\hline Terpenoids & + & + & + & + \\
\hline Quinones & - & - & - & - \\
\hline Coumarins & + & + & + & - \\
\hline Steroids & + & - & + & - \\
\hline Phytosteroids & + & + & + & - \\
\hline Anthroquinones & - & - & + & - \\
\hline Phlobatannins & - & - & + & - \\
\hline
\end{tabular}


Table 2: Antibacterial activity of various crude solvent extracts of H.clathratus.

\begin{tabular}{|c|c|c|c|c|c|}
\hline \multirow{2}{*}{ Bacterial strains } & \multirow{2}{*}{ Conc. $\mathrm{mg} / \mathrm{ml}$} & \multicolumn{4}{|c|}{ Zone of inhibition in $\mathbf{m m}$} \\
\hline & & Hexane & Ethyl acetate & Methanol & Aqueous \\
\hline \multirow{4}{*}{ Escherichia coli } & 1.5 & $12.00 \pm 0.89$ & $10.66 \pm 136$ & $14.56 \pm 1.03$ & 0 \\
\hline & 2.5 & $14.66 \pm 1.86$ & $12.33 \pm 0.51$ & $16.00 \pm 0.51$ & $4.66 \pm 0.51$ \\
\hline & 5 & $15.33 \pm 2.06$ & $13.00 \pm 0.89$ & $19.32 \pm 0.89$ & $7.66 \pm 0.51$ \\
\hline & Antibiotic & $14.66 \pm 1.86$ & $14.66 \pm 1.86$ & $14.66 \pm 1.86$ & $14.66 \pm 1.86$ \\
\hline \multirow{4}{*}{ Pseudomonas aeruginosa } & 1.5 & $11.66 \pm 1.36$ & $4.66 \pm 0.51$ & $10.11 \pm 1.03$ & 0 \\
\hline & 2.5 & $12.00 \pm 0.89$ & $7.33 \pm 0.51$ & $13.23 \pm 0.76$ & 0 \\
\hline & 5 & $16.66 \pm 1.36$ & $8.33 \pm 0.89$ & $26.33 \pm 1.86$ & $8.33 \pm 0.89$ \\
\hline & Antibiotic & $16.66 \pm 1.03$ & $16.66 \pm 1.03$ & $16.66 \pm 1.03$ & $16.66 \pm 1.03$ \\
\hline \multirow{4}{*}{ Klebsiella pneumoneae } & 1.5 & $11.66 \pm 0.51$ & $12.00 \pm 1.54$ & $12.21 \pm 0.81$ & 0 \\
\hline & 2.5 & $14.66 \pm 0.51$ & $13.66 \pm 1.36$ & $15.52 \pm 1.06$ & $5.00 \pm 0.89$ \\
\hline & 5 & $16.66 \pm 1.36$ & $16.66 \pm 1.36$ & $18.14 \pm 1.50$ & $8.00 \pm 0.89$ \\
\hline & Antibiotic & $18.00 \pm 0.89$ & $18.00 \pm 0.89$ & $18.00 \pm 0.89$ & $18.00 \pm 0.89$ \\
\hline \multirow{4}{*}{ Bacillus subtilis } & 1.5 & $11.66 \pm 1.03$ & $15.66 \pm 1.86$ & $13.00 \pm 0.89$ & 0 \\
\hline & 2.5 & $12.66 \pm 0.51$ & $16.33 \pm 2.03$ & $15.66 \pm 1.36$ & $3.00 \pm 0.89$ \\
\hline & 5 & $15.66 \pm 2.87$ & $17.66 \pm 0.51$ & $18.33 \pm 1.86$ & $7.33 \pm 0.51$ \\
\hline & Antibiotic & $16.66 \pm 1.36$ & $16.66 \pm 1.36$ & $16.66 \pm 1.36$ & $16.66 \pm 1.36$ \\
\hline \multirow{4}{*}{ Staphylococcus aureus } & 1.5 & $12.33 \pm 1.36$ & $10.66 \pm 136$ & $15.66 \pm 2.87$ & 0 \\
\hline & 2.5 & $15.66 \pm 2.87$ & $13.66 \pm 1.36$ & $17.00 \pm 0.89$ & 0 \\
\hline & 5 & $17.00 \pm 0.89$ & $14.33 \pm 1.86$ & $21.00 \pm 1.78$ & $6.66 \pm 0.51$ \\
\hline & Antibiotic & $16.66 \pm 0.51$ & $16.66 \pm 0.51$ & $16.66 \pm 0.51$ & $16.66 \pm 0.51$ \\
\hline
\end{tabular}

Table 3: Antifungal activity of various crude solvent extracts of H.clathratus.

\begin{tabular}{|c|c|c|c|c|c|}
\hline \multirow{2}{*}{ fungi } & \multirow{2}{*}{ Conc. $\mathrm{mg} / \mathrm{ml}$} & \multicolumn{4}{|c|}{ Zone of inhibition in $\mathrm{mm}$} \\
\hline & & Hexane & Ethyl acetate & Methanol & Aqueous \\
\hline \multirow{4}{*}{ Aspergillus flavus } & 1.5 & $6.66 \pm 0.51$ & $10.66 \pm 136$ & $12.33 \pm 2.25$ & 0 \\
\hline & 2.5 & $8.66 \pm 0.51$ & $13.33 \pm 2.87$ & $14.66 \pm 2.25$ & 0 \\
\hline & 5 & $12.66 \pm 1.36$ & $15.00 \pm 1.78$ & $18.00 \pm 3.22$ & $3.66 \pm 0.41$ \\
\hline & Antibiotic & $10.66 \pm 1.86$ & $10.66 \pm 1.86$ & $10.66 \pm 1.86$ & $10.66 \pm 1.86$ \\
\hline \multirow{4}{*}{ Aspergillus niger } & 1.5 & $7.66 \pm 0.51$ & $14.66 \pm 0.51$ & $5.66 \pm 0.51$ & 0 \\
\hline & 2.5 & $9.00 \pm 0.09$ & $15.23 \pm 0.51$ & $13.66 \pm 1.20$ & $6.23 \pm 1.54$ \\
\hline & 5 & $11.43 \pm 1.36$ & $18.33 \pm 2.73$ & $15.00 \pm 0.78$ & $8.33 \pm 0.89$ \\
\hline & Antibiotic & $12.66 \pm 1.03$ & $12.66 \pm 1.03$ & $12.66 \pm 1.03$ & $12.66 \pm 1.03$ \\
\hline \multirow{4}{*}{ Candida albicans } & 1.5 & $8.25 \pm 0.50$ & $3.00 \pm 1.54$ & $11.66 \pm 2.25$ & 0 \\
\hline & 2.5 & $10.32 \pm 0.71$ & $5.56 \pm 1.36$ & $14.66 \pm 2.73$ & $5.00 \pm 0.89$ \\
\hline & 5 & $11.66 \pm 2.58$ & $6.66 \pm 0.51$ & $15.14 \pm 1.50$ & $8.00 \pm 0.89$ \\
\hline & Antibiotic & $18.00 \pm 0.89$ & $18.00 \pm 0.89$ & $18.00 \pm 0.89$ & $18.00 \pm 0.89$ \\
\hline \multirow{4}{*}{ Fusarium oxysporum } & 1.5 & $13.00 \pm 0.59$ & $7.45 \pm 1.86$ & $10.09 \pm 0.89$ & 0 \\
\hline & 2.5 & $15.66 \pm 1.36$ & $10.23 \pm 2.03$ & $13.06 \pm 1.36$ & $3.00 \pm 0.89$ \\
\hline & 5 & $18.33 \pm 1.86$ & $11.76 \pm 0.51$ & $15.13 \pm 0.86$ & $5.33 \pm 0.51$ \\
\hline & Antibiotic & $10.06 \pm 0.36$ & $10.06 \pm 0.36$ & $10.06 \pm 0.36$ & $10.06 \pm 0.36$ \\
\hline \multirow{4}{*}{ Penicillium sp. } & 1.5 & $9.36 \pm 0.25$ & $7.26 \pm 1.87$ & $5.66 \pm 0.32$ & 0 \\
\hline & 2.5 & $11.06 \pm 0.21$ & $9.46 \pm 0.75$ & $10.66 \pm 1.36$ & 0 \\
\hline & 5 & $13.00 \pm 1.54$ & $11.66 \pm 0.51$ & $13.66 \pm 1.36$ & $6.00 \pm 0.21$ \\
\hline & Antibiotic & $18.66 \pm 2.25$ & $18.66 \pm 2.25$ & $18.66 \pm 2.25$ & $18.66 \pm 2.25$ \\
\hline
\end{tabular}

\section{DISCUSSION}

The preliminary phytochemical screening indicates the presence of various compounds. The colour of the extracts is predominantly light or dark green or yellowish green. The green colour is mainly due to presence of different kinds of chlorophyll pigments (Chlorophyll a \& b) along with carotenoids. Seaweeds are rich in secondary metabolites which include alkaloids, glycosides, flavonoids, saponins, tannins, steroids, related active metabolites, which are of great medicinal value and have been extensively used in the drug and pharmaceutical industry. Phenols and flavonoids are antioxidants and play a vital role in the bioactivity of seaweeds. Some of these bioactivities include antimicrobial, anti-inflammatory and haemolytic effects (George et al., 2002).

The antimicrobial activity of seaweeds may be influenced by some factors such as the habitat and the season of algal collection, different growth stages of plant, experimental methods, etc. Many solvents have been used for screening antimicrobial activity. However, it is still uncertain about the effective solvent that is suitable for extraction of seaweeds. Martinez- Nadal et al., (1966) mentioned that benzene and diethyl ether were suitable solvents for extracting the antibiotic principle. Parekh et al., (1984) reported that extracts obtained with acetone, ethyl alcohol and ether showed higher antibacterial activity than that of extracts obtained with chloroform. Thirumaran et al., 
(2006) screened the antimicrobial activity of H.clathratus using methanol extracts and reported that P.aeruginosa were more susceptible than the other extracts. The results from the present screening revealed that the strongest antibacterial activity was exhibited by the methanol extract and the least by aqueous.

Seaweeds belonging to brown algae exhibit inhibitory action against both Gram-positive and Gram-negative bacteria (Del Val et al., 2001). The organic solvent chloroform and methanol extracts of some red and brown algae showed maximum activity against certain human pathogenic bacteria (Vallinayagam et al., 2009). In our study it was reported that the methanolic extract of H.clathratus showed highest antibacterial activity against both Gram-negative and Gram-positive bacteria when compared to other solvent which were studied.

The methanolic extract showed the highest percentage of inhibition against most of the fungal pathogens studied. Although solvent extracts showed activity against the fungal strains, the aqueous extract showed the minimum or no activity against the pathogens. Aqueous extracts did not alter the growth of fungal species suggesting that either that they are not able to diffuse across the agar or that the extracting condition did not allow the isolation of active compounds with properties to alter fungal growth under these conditions. The activity may vary according to the species, extraction process and many other parameters.

Padmakumar and Ayyakkannu (1997) screened 80 species of marine algae for antifungal activities but did not find a single algal extract active against $A$. flavus. Present investigation, on the other hand, showed that extract of the seaweed is effective against $A$. flavus.

The present study revealed that tested fungi exhibited variable responses for the seaweed extracts depending upon the applied solvent and fungal species. In this respect, Candida albicans exhibited the highest resistance for all extracts except in case of methanolic extract. Tuney et al., (2006) found that ethanolic extract of Padina pavonica were active against $C$. albicans, however methanolic and acetonic extracts of the same algae were inactive against $C$. albicans. Variable findings were obtained by several authors concerning the best solvent for extraction the bioactive compounds. Khallil et al., (2015) reported that there was no inhibitory action against Fusarium oxysporum with ethyl acetate extract of Dictyota. Dichotoma but the present study recorded inhibitory activity of ethyl acetate extract against F.oxysporum.

\section{CONCLUSION}

The main objective of this work was to evaluate and compare the ability of different solvent extracts of H.clathratus to produce bioactive compounds of potential therapeutic interest. The production of antibacterial activities was considered to be an indicator for the capability of the seaweeds to synthesize bioactive compounds. Marine natural products contain a wide range of novel bioactive compounds or antibiotics with distinctive complex structures. The study offers opportunities for producing new types of bioactive compounds; however, the mechanism of inhibition and stability of the extracts still are not clear and more studies should be involved.

\section{ACKNOWLEDGEMENT}

Financial support and sponsorship: This research project was supported by a grant from University Grants Commission under UGC-FDP programme.

Conflict of Interests: There are no conflicts of interest.

\section{REFERENCES}

Ireland C, Roll D, Molinsk T, Mckee T, Zarbriske T, Swersey J. Uniqueness of the marine environment: categories of marine natural product from invertebrates. D.G. Fautin (Ed.), Biomedical Importance of Marine Organisms, California Academy of Sciences, San francisco, 1988; $41-58$.

Schwartsmann G, Da Rocha A, Berlinckand J, Jimeno J. Marine organisms as a source of anticancer agents. Lancet Oncol., 2001; 2: 221225 .

Kolanjinathan K, Ganesh P, Govindarajan.M. Antibacterial activity of ethanol extracts of seaweeds against fish bacterial pathogens. Eur. Rev. Med. Pharmacol. Sci, 2009; 13: 173-177.

Mouhssen Lahlou .The Success of Natural Products in Drug Discovery.Pharmacology \& Pharmacy, 2013; 4: 17-31. http://dx.doi.org/10.4236/pp.2013.

Kolanjinathan K, Ganesh P, Saranraj P. Pharmacological Importance of Seaweeds: A Review. World Journal of Fish and Marine Sciences, 2014; 6 (1): 01-15, ISSN 2078-4589 @ IDOSI Publications, 2014 DOI: 10.5829/idosi.wjfms.2014.06.01.76195.

José Vitor M Lima-Filho, Ana F F U Carvalho, Sissi M Freitas, Vânia M M Melo. Antibacterial activity of extracts of six macroalgae from the northeastern brazilian coast. Brazilian Journal of Microbiology, 2002; 33:311-313. ISSN 1517-8382.

Chkhikvishvili and Ramazanov. Phenolic substances of brown algae and their antioxidant activity. Applied Biochemistry and Microbiology, 2000; 36(3):289-291.

TÜney, İnci. Antimicrobial activities of the extracts of marine algae from the coast of Urla (Izmir, Turkey). Turkish Journal of Biology , 2006; 30(3): 171-175.

Vlachos V, Critchley AT, Von Holy A. Antimicrobial activity of extracts from selected Southern African marine macroalgae. South African Journal of Science, 1997; 93:328-332.

Cox, Sabrina, Nissreen Abu-Ghannam, Shilpi Gupta. An assessment of the antioxidant and antimicrobial activity of six species of edible Irish seaweeds. Int.Food Res., 2010; 17:205-220.

Manivannan K, Anantharaman $\mathrm{P}$, Balasubramanian $\mathrm{T}$. Antimicrobial potential of selected brown seaweeds from Vedalai coastal waters, Gulf of Mannar. Asian Pacific journal of tropical biomedicine. 2011; 1.2: 114-120.

Fang HY, Chokkalingam U, Chio SF, Hwang TL, Chen SL, Wang WL, Sheu JH. Bioactive Chemical Constituents from the Brown Alga Homoeostrichus formosana. Int. J. Mol. Sci. 2015; 16: 736-746.

Manilal A, Gezmu T, Merdekios B, et al. Evaluating the In Vitro Antagonism of Secondary Metabolites Fractionated from the Brown Algae, Sargassum swartzii against Human Candida spp. Transl Biomed. 2016; 7:1.

Gupta S, Abu-Ghannam N. Bioactive potential and possible health effects of edible brown seaweeds. Trends in Food Science and Technology. 2011; 22:315-326.

Seafoodplus (2008). www.seafoodplus.org/fileadmin/files/ news/2004-01-22SFRTD1 launchBrussels.pdf. Accessed 25.03.10.

Harborne JB. Phytochemical Methods.Journal of Chemical Information and Modeling, 1998; 3: 317. 
Perez C, Pauli M, Bazerque P. An antibiotic assay by agar-well diffusion method. Acta Biologiae et Medecine Experimentaalis, 1990; 15:113-115.

Suay I, Arenal F, Asensio FJ, Basilio A, Cabello MA, Diez MT, Garcia JB, Gonzalez del Val A, Gorrochategui J, Hernandez P, Pelaez F, Vicente MF. Screening of basidiomycetes for antimicrobial activities. Antonie van Leeuwenhoek, 2000; 78:129-139.

George F, Zohar Kerem, Harinder PSM, Klaus Becker. The biological action of saponins in animal systems: a review. Brit $\mathrm{J}$ Nutr, 2002; 88(6): 587-605.

Martinez-Nadal NGC, Casillas Rodriguez-Perrazza JR, Torreera L. Antibiotic properties of marine algae Cymoplia barbata. Bot Mar. 1966; 9:21-26.

Parekh KS, Parekh HH, Rao PS. Antibacterial activity of Indian seaweeds. Phykos. 1984; 23:216-221.

Thirumaran G, Anantharaman P. Antibacterial activity and antifungal activities of marine macro alga (Hydroclathrus clathratus) from the Gulf of Mannar Biosphere Reserve. Environ Ecol. 2006; 24 S (1):5558.

Del Val AG, Platas G, Basilio A, Gorrochategui J, Suai I, Vicente F, Portillo E, del Rio MJ, Reina GG, Pelaez F. Screening of antimicrobial activities in red, green and brown macroalgae from Gran Canaria (Canary Islands, Spain). Int. Microbiol., 2001; 4: 35-40.
Vallinayagam K, Arumugam R, Kannan RRR, Thirumaran G, Anantharaman P. Antibacterial Activity of Some Selected Seaweeds from Pudumadam Coastal Regions. GJP 2009; 3: 50-52.

Padmakumar, Ayyakkannu K. Seasonal variation of antibacterial and antifungal activities of the extracts of marine algae from Southern coasts of India. Bot Mar. 1997; 40:507-515.

Tuney I, Çadirci BH, Ünal D, Sukatar. Antimicrobial Activities of the Extracts of Marine Algae from the Coast of Urla (Izmir, Turkey). Turk. J. Biol. 2006; 30: 171-175.

Khallil AM, Daghman IM, Fady AA .Antifungal Potential in Crude Extracts of Five Selected Brown Seaweeds Collected from the Western Libya Coast. J Micro Creat., 2015; 1(1): 103.

\section{How to cite this article:}

Vimala T, Poonghuzhali TV. In vitro antimicrobial activity of solvent extracts of marine brown alga, Hydroclathrus clathratus (C. Agardh) M. Howe from Gulf of Mannar. J App Pharm Sci, 2017; 7 (04): $157-162$ 